\title{
Damage Healing of Aluminum Alloys by D. C. Electropulsing and Evaluation by Resistance
}

\author{
Qiao Shengru, Li Yanli, Li Yun, Zhang Chengyu \\ National Key Laboratory of Thermostructure Composite Materials, Northwestern Polytechnical University, Xi'an 710072, China
}

\begin{abstract}
The damage and cold work hardening of 4043 and 2024 T4 aluminum alloy were introduced by tensile test under the applied stress between the yield strength and ultimate tensile strength. Fatigue damage of 2024 T4 aluminum alloy was introduced by cycling to half of fatigue life ( 85000 cycles) at $225 \mathrm{MPa}$. Then the damaged specimens were healed by D. C. electropulsing. The electric resistances of as-received, damaged and healed specimens were measured by electric bridge, respectively. The results show that the elongation increases, and yield strength and ultimate strength decrease with the increase of healing time for the 4043 aluminum alloy tensile damaged specimen. The mechanical properties of the 4043 aluminum alloy damaged specimens treated by a $0.5 \mathrm{~s}$ electropulsing are close to the values of undamaged specimens. Fatigue life is considerably prolonged by a $0.8 \mathrm{~s}$ electropulsing treatment for the fatigue damaged specimen of $2024 \mathrm{~T} 4$ aluminum alloy. The electric resistance of aluminum alloys increases obviously after fatigue or tension damage, and decreases after electropulsing treatment, but it is still larger than that of the as-received specimen. The treatment time has little influence on the final resistances, but the mechanical properties are quite different for the samples treated by various electropulsing time. Although the resistance can describe the damage of aluminum alloys, it is not very sensitive to the mechanical properties, so it can not be considered as a good criterion for healing evaluation. The observation of microstructure reveals that the damages can be partly healed after D. C. electropulsing, and recrystallizaton phenomenon appears.
\end{abstract}

Key words: aluminum alloy; D. C. electropulsing; damage; fatigue; resistance; tensile

Many research results indicate that an electric current can influence the behaviors of materials, such as electromigration $^{[1]}$, electroplasticity ${ }^{[2]}$, solidification of metals and alloys ${ }^{[3]}$, structural modification $^{[4]}$, and so on. Previous works showed that high current density electropulsing could be used for annealing of cold worked copper and titanium ${ }^{[5,6]}$, partly healing of microcracks of steel ${ }^{[7]}$, and modifying of persistent sliding bands (PSBs) produced by fatigue ${ }^{[8]}$. But above mentioned studies were seldomly dealt with damage healing in aluminum alloy. Besides, how to judge the damage healing process is an anxious problem to be solved. There are many parameters which can be used to evaluate damage, such as modulus change, macro-hardness, toughness dissipation, potential change, electrical resistance, ultrasonic dynamic method, etc. Among them, electrical resistance method is one of the best nondestructive examination methods. Present investigation will use electrical resistance to evaluate the damage healing by electropulsing in aluminum alloys.

\section{Experimental Study}

The studied materials were 4043 and 2024 aluminum alloys, whose compositions are given in Table 1. 4043 alloy was taken from a cold rolled plate. 2024 alloy plate was in a heat treated state according to $\mathrm{T} 4$ regime. Their main properties are listed in Table 2.

Tensile specimens were fabricated according to the ASTM E8. Their dimension is shown in Fig.1. The thickness of specimens was $0.92 \mathrm{~mm}$ for 4043 alloy, and $1.88 \mathrm{~mm}$ for 2024 alloy.

The damage or work hardening of specimens were introduced by the pre-tensile test, whose applied stress was 160 MPa for 4043 alloy, and 440, 470, $490 \mathrm{MPa}$ for 2024 alloy, 
Table 1 Composition of two kinds of aluminum alloys (wt\%)

\begin{tabular}{ccccccccc}
\hline Alloy & $\mathrm{Si}$ & $\mathrm{Fe}$ & $\mathrm{Cu}$ & $\mathrm{Mn}$ & $\mathrm{Mg}$ & $\mathrm{Zn}$ & $\mathrm{Ti}$ & $\mathrm{Al}$ \\
\hline 4043 & 5.14 & 0.80 & 0.30 & 0.05 & 0.05 & 0.10 & 0.20 & $\mathrm{Bal}$. \\
2024 & 0.5 & 0.5 & $3.8-4.9$ & $0.3-0.9$ & $1.2-1.8$ & & & Bal. \\
\hline
\end{tabular}

Table 2 Typical mechanical properties

\begin{tabular}{cccc}
\hline Alloy & $\begin{array}{c}\text { Nominal yield } \\
\text { strength } \sigma_{0.2} / \mathrm{MPa}\end{array}$ & $\begin{array}{c}\text { Ultimate tensile } \\
\text { strength } \sigma_{\mathrm{b}} / \mathrm{MPa}\end{array}$ & Elongation/\% \\
\hline 4043 & 156.6 & 166.8 & 2.7 \\
2024 & 382 & 501 & 17.8 \\
\hline
\end{tabular}

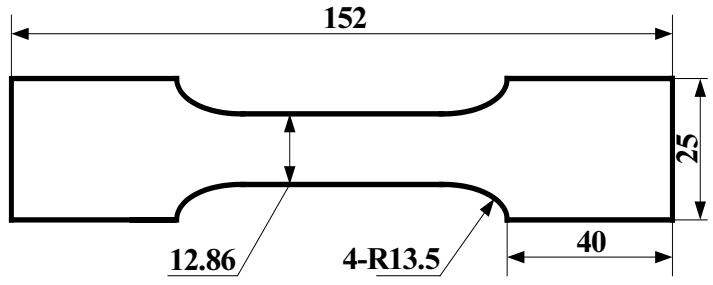

Fig.1 Schematic of the tensile specimen ( $\mathrm{mm})$

respectively, located between the $\sigma_{0.2}$ and $\sigma_{\mathrm{b}}$. The damaged specimens after tensile stress applied were treated by D. C. electropulsing with different time. The pulsing frequency and the density of current were $50 \mathrm{~Hz}$ and $170 \mathrm{~A} / \mathrm{mm}^{2}$, respectively. The treatment duration was a cumulative time; after every $0.2 \mathrm{~s}$ treatment, there was a rest of $1 \mathrm{~min}$ for cooling the specimens. The electric resistances of as-received, damaged and healing states of specimens were measured by an electric bridge. Then the treated specimens were fractured by a tensile test.

The fatigue specimens of $2024 \mathrm{~T} 4$ aluminum alloy were fabricated according to ASTM466. Their dimension is shown in Fig.2. The work section of the specimen is $7.86 \mathrm{~mm}$ (width) $\times 1.88 \mathrm{~mm}$ (thickness). Fatigue damage was introduced by cycling to half of a fatigue life (85 000 cycles) at $225 \mathrm{MPa}$. Then the damaged specimens were healed by D. C. electropulsing. The electropulsing method, parameters and resistance measure were the same as the tensile test. The treated specimens were continually fatigued to fracture at $225 \mathrm{MPa}$, and the fatigue life times were estimated by 85000 plus continual fatigue cycles of the treated specimens.

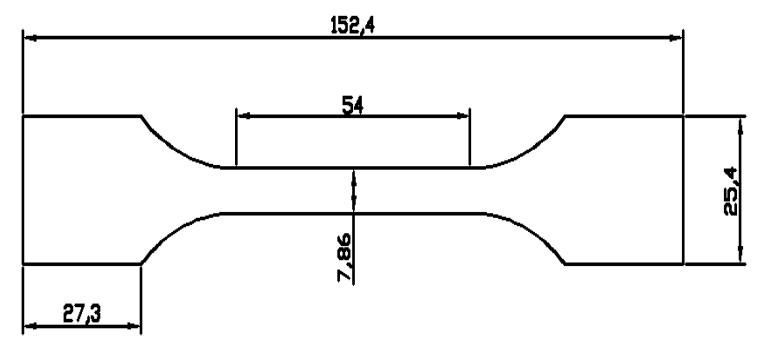

Fig.2 Schematic of the fatigue specimen $(\mathrm{mm})$
The microscopic structure of as-received, damaged and treated specimens is observed by an optical microscope.

\section{Results}

From Table 3 we can find that the resistance of 4043 tensile specimens as-received is around $27.20 \mathrm{~m} \Omega$. After applying $160 \mathrm{MPa}$ stress, the resistance changes to $30.12 \mathrm{~m} \Omega$, which increases by about $11 \%$. When treated by D. C. electropulsing, the resistance becomes to $28.17 \mathrm{~m} \Omega$, decreases by about $6.5 \%$ and almost does not depend on the treated time. However, the resistance of treated specimens is larger than that of the asreceived specimens. The higher the pre-tensile stress is, the more the increase of the resistance of 2024 alloy is. Via treatment of $0.8 \mathrm{~s} \mathrm{D}$. C. electropulsing, the resistance also decreases, and the final resistance is independent to the tensile stress, because the final resistance is nearly the same, as indicated in Table 3.

According to Table 3 and Table 4, although the resistance of 4043 specimens treated for different time is nearly the same, the tensile properties are obviously different. With the increase of the treated time, the yield strength and ultimate tensile strength intensely decease, and the elongation slightly increases. Although the resistance of the damaged 4043 alloy specimens after treatment decreases and the different treatment time results in the close resistances, the mechanical properties are quite different for the samples treated for various electropulsing time.

Table 3 Resistance of tensile specimens at RT

\begin{tabular}{cccccc}
\hline Sample $\begin{array}{c}R \text { as } \\
\text { received/ } \\
\mathrm{m} \Omega\end{array}$ & $\begin{array}{c}\text { Pre-tensile } \\
\text { stress/MPa }\end{array}$ & $\begin{array}{c}R \text { after } \\
\text { pre-tensile/ } \\
\mathrm{m} \Omega\end{array}$ & $\begin{array}{c}\text { Treated } \\
\text { time/s }\end{array}$ & $\begin{array}{c}R \text { after } \\
\text { treatment } \\
/ \mathrm{m} \Omega\end{array}$ \\
\hline \multirow{4}{*}{4043} & 27.35 & 160 & 30.17 & 0.5 & 28.13 \\
& 27.14 & 160 & 30.10 & 1 & 28.32 \\
& 27.10 & 160 & 30.08 & 10 & 28.06 \\
2024 & 25.89 & 440 & 26.56 & 0.8 & 26.01 \\
$\mathrm{~T} 4$ & 25.78 & 470 & 26.90 & 0.8 & 25.75 \\
& 25.83 & 490 & 27.29 & 0.8 & 26.04 \\
\hline
\end{tabular}

Table 4 Tensile properties after treatment

\begin{tabular}{cccccc}
\hline \multirow{2}{*}{ Sample } & $\begin{array}{c}\text { Pre-tensile } \\
\text { stress/ } \\
\mathrm{MPa}\end{array}$ & $\begin{array}{c}\text { Treated } \\
\text { time/s }\end{array}$ & $\begin{array}{c}\text { Yield } \\
\text { strength } \\
\sigma_{0.2} / \mathrm{MPa}\end{array}$ & $\begin{array}{c}\text { Ultimate } \\
\text { strength } \\
\sigma_{\mathrm{b}} / \mathrm{MPa}\end{array}$ & $\begin{array}{c}\text { Elongation/ } \\
\%\end{array}$ \\
\hline \multirow{2}{*}{4043} & 160 & 10 & 137.2 & 142.4 & 3.0 \\
& 160 & 1 & 150.9 & 163.5 & 2.9 \\
& 160 & 0.5 & 155.8 & 164.4 & 2.7 \\
2024 & 440 & 0.8 & 427.5 & 505 & 17.6 \\
$\mathrm{~T} 4$ & 470 & 0.8 & 437.5 & 497 & 18.1 \\
& 490 & 0.8 & 433.5 & 490 & 19.3 \\
\hline
\end{tabular}


Table 5 is the fatigue test results at $225 \mathrm{MPa}$. After 85000 cycles at $225 \mathrm{MPa}$ stress, the electrical resistance increases. The electrical resistance after healing treatment is always decreased comparing with that of the counterparts after fatigue, but it is higher than that of the as received specimens. The resistance of the specimens treated with different time is nearly the same; however, the fatigue life of treated specimens is prolonged. The optimum treatment time is $0.8 \mathrm{~s}$, and the fatigue life increases by about $40 \%$. When treated time reaches $5 \mathrm{~s}$, the fatigue life increases by about $30 \%$.

\section{Discussion}

After the tensile or fatigue test, the ordered lattice was destroyed, and the defects of the damaged specimens enhanced. The defects include vacancies, voids, dislocation, lattice distortion, sliding bands, grain deformation, microcracks, etc. The enhanced defects can disturb the direction movement of the electrons, and induce higher resistance. Therefore, the resistances of the specimen after tension or fatigue damage increase. Upon applying electropulsing to the damaged specimens, the electromigration take place ${ }^{[4]}$. The partial defects will be healed or even vanish, and these processes associate with the electromigration. The defects of the treated specimens reduce, while the resistance decreases.

Nearly all defects relate to the dislocations; therefore, the electropulsing is mainly used to heal the dislocations. It is well known that the flow stress $\sigma$ for metal is related to the dislocations density $\rho$, shown in Eq (1):

$$
\sigma=\sigma_{0}+m \alpha G b \rho^{1 / 2}
$$

Where $\sigma_{0}$ is a contribution into the deformation resistance nature, $m \alpha$ is orientation factor, $\alpha$ is close to 0.3 , which is a parameter characterizing the inter-dislocation interaction, $G$ is the shear modulus, and $b$ is the Burgers vector. When pre-tensile stress of 2024 alloy is higher, the dislocations density $\rho$ will increase, leading to the increase of the resistance, shown in Table 3.

According to the orientation factor $m \alpha$, the dislocations can be divided into two kinds: easy healing and difficult healing. When the moof dislocations is favorable to the current direction, after treatment by electropulsing, the dislocations of easy healing could vanish owing to electromigration, but the dislo-

Table 5 Fatigue test results of $2024 \mathrm{~T} 4$ aluminum alloy at $225 \mathrm{MPa}$

\begin{tabular}{ccccc}
\hline $\begin{array}{c}R \text { as } \\
\text { received/ } \\
\mathrm{m} \Omega\end{array}$ & $\begin{array}{c}R^{\prime} \text { after } \\
85000 \\
\text { cycles } / \mathrm{m} \Omega\end{array}$ & $\begin{array}{c}\text { Treated } \\
\text { time } / \mathrm{s}\end{array}$ & $\begin{array}{c}R^{\prime \prime} \text { after } \\
\text { healing } \\
/ \mathrm{m} \Omega\end{array}$ & $\begin{array}{c}\text { Total cycles/ } \\
\mathrm{N}\end{array}$ \\
\hline & & 0 & & 170000 \\
25.95 & 27.20 & 0.5 & 26.09 & 186323 \\
26.48 & 27.93 & 0.8 & 27.06 & 287823 \\
27.08 & 27.87 & 1.2 & 27.53 & 281310 \\
26.02 & 27.77 & 5.0 & 26.78 & 220670 \\
\hline
\end{tabular}

cations of difficult healing are left. Hence only partial defects will be healed or even vanish after electropulsing, which can explain why the resistance of treated specimens decreases, and is always larger than that of the received specimens. Owing to the fact that only the favorable moof dislocations to the current direction can be used for healing, it is that no matter how long the treatment time is and how big the pre-tensile stress is, the final resistance via treatment by D. C. electropulsing is nearly the same, and independent on treatment time, as shown in Table 3 and Table 4. However, extra treatment time result in the annealing due to the elevated temperature; therefore the yield strength and ultimate tensile strength decease intensely, and the elongation increases slightly with increasing of treatment time.

$R^{\prime}-R$ indicates the damage value, while the difference $R^{\prime}-R$ ' $(R$ ' is the resistance of the treated specimen by electropulsing) expresses damage restorable value. $\left(R^{\prime}-R^{\prime \prime}\right) /\left(R^{\prime}\right.$ $-R) \times 100 \%$ denotes damage restorable percent, as well as the $\left[1-\left(R^{\prime}-R^{\prime \prime}\right) /\left(R^{\prime}-R\right) \times 100 \%_{0}\right.$ indicates residual damage percent. The data shown in Table 3 and Table 5 are not satisfied to this concept; although resistance can reflect the damage recovery by electropulsing, it can not evaluate recovery extent, especial for the specimen with extra treatment time.

Observation in the same site of damaged and treated specimens shows that the damage is partly healed by electropulsing. Fig. 3 is one of illustrations. Before tensile test, no damage exists (Fig.3a). After the tensile test, there are several damage which can be found, and obvious damage is indicated by an arrow (Fig.3b). When treated by electropulsing, partial damage is recovered (Fig.3c). After the fatigue test, we can find slip bands, as indicated by an arrow in Fig.4a, and grain boundaries. In the same corrosion condition for the fatigued specimens, the specimens treated by the electropulsing are difficult to be corroded (Fig.4b), and even the grain boundary can not be found clearly. This phenomenon indirectly demonstrate that defects decrease after the electropulsing treatment, because the more the defects, the easier the corrosion. In Fig. $4 \mathrm{~b}$, it can be found that grain size decreases, which means that the recrystallization takes place after the electropulsing.

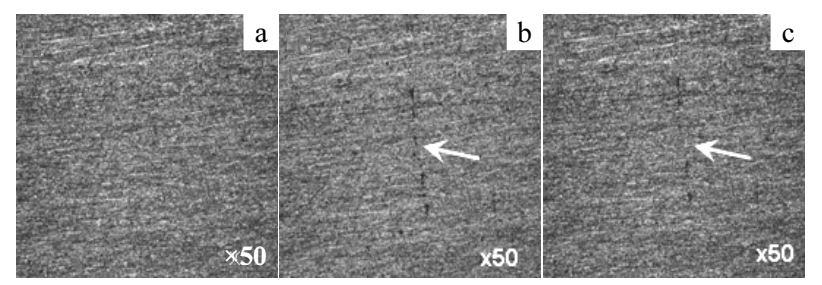

Fig.3 Optical micrograph of 4043 Al-Si specimen: (a) before tension, (b) after tension, and (c) after 0.5 s electropulsing

Observation of damaged and treated specimens by an optical microscope reveals that the damages has been partially healed after the D. C. electropulsing treatment, and recrystallization phenomenon occurs. 


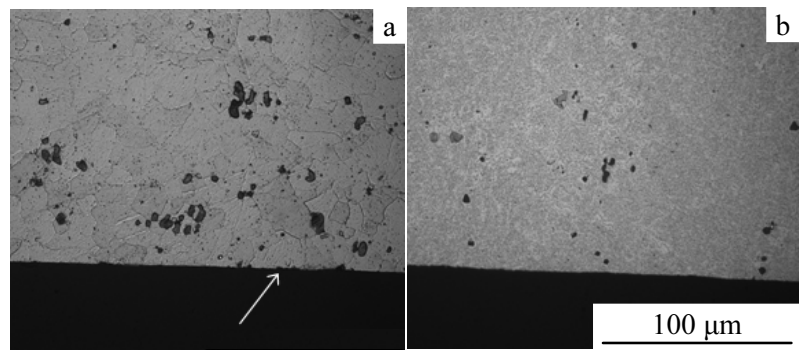

Fig.4 Microstructure of 2024 T4 alloy specimen: (a) after fatigue and (b) after $5.0 \mathrm{~s}$ electropulsing

\section{Conclusions}

1) The elongation increases, and yield strength and ultimate strength decrease with the increase of the electropulsing healing time for the 4043 pre-tensile damaged specimen. The higher the pre-tensile stress is, the more the increase of the resistance of 2024 alloy is. Via treatment by the D. C. electropulsing for $0.8 \mathrm{~s}$, the resistance also decreases, and the final resistance is nearly the same. Fatigue life is considerably increased by a $0.8 \mathrm{~s}$ electropulsing treatment under $170 \mathrm{~A} / \mathrm{mm}^{2}$ current for the 2024 fatigued specimen.

2) The electric resistance increases obviously for the damaged specimens and decreases after the electropulsing treatment, but it is still larger than that of the as received specimen. No matter how long the treatment time is and how big the pre-tensile stress is, the final resistance via treatment by D. C. electropulsing is nearly the same. Although the resistance can reflect the damage recovery by the electropulsing treatment, it can not evaluate the extent of the recovery, especially for the specimen of extra treatment time due to annealing.

3) The observation of microstructure reveals that the damages can be partly healed after D. C. electropulsing.

Acknowledgement: This work is supported by The Program of Introducing Talents of Discipline in the Project of Advanced Materials and Their Forming Technology in 111project and Honeywell Corp., USA.

\section{References}

1 Troitskii O A. Mater Sci Eng[J], 1985, 75A: 37

2 Sprecher A F, Mannan S L, Conrad H. Acta Metall[J], 1986, 34: 1145

3 Barnak J P, Sprecher A F, Conred H. Scripta Mater[J], 1995, 32: 879

4 Conrad H. Mater Sci Eng[J], 2000, A287: 227

5 Zhang C J, Wang B Q, Guo J D. Chinese Journal of Materials Research [J], 2005, 19: 238

6 Loskutov S V. Metal Science and Heat Treatment[J], 2006, 48: 261

7 Zuev L B, Sosnin O V, Podboronnikov S F et al. Technical Physics $[\mathrm{J}], 2000,45: 309$

8 Shen Y F, Guo X N, Yao G et al. Chinese Journal of Materials Research[J], 1999, 13: 381

\title{
直流脉冲电流对铝合金的损伤修复和电阻评估
}

\author{
乔生儒, 李艳丽, 李 云, 张程煜 \\ (西北工业大学 超高温结构复合材料科技国家重点实验室, 陕西 西安 710072)
}

\begin{abstract}
摘 要: 用拉伸试验对 4043 和 $2024 \mathrm{~T} 4$ 铝合金造成损伤和冷加工硬化, 施加的应力处于屈服强度和抗拉强度之间。2024 T4 铝合金在 225 MPa 下循环到其半寿命 (85000 次) 造成疲劳损伤。被损伤的试件用直流电脉冲处理。用电桥分别测量原始试件、损伤试件和电脉冲处 理试件的电阻。结果表明, 随着脉冲处理时间的增加, 4043 铝合金拉伸造成损伤的试件延伸率增加, 屈服强度和抗拉强度减小; $0.5 \mathrm{~s}$ 脉冲处理试样的力学性能十分接近未损伤试样的性能。2024 T4 铝合金的疲劳损伤试件经 $0.8 \mathrm{~s}$ 电脉冲处理后的寿命显著提高。经过疲劳 或拉伸损伤的铝合金电阻明显增加, 再经电脉冲处理后电阻减小, 但是其电阻仍高于原始试件。处理时间对最终的电阻值影响很小, 但 是力学性能随处理的时间不同差别很大。虽然电阻可描述铝合金的损伤, 但是它对力学性能不十分敏感, 因此电阻不是一个很好的表证 损伤愈合的方法。组织观察显示, 经过电脉冲处理后损伤得到部分愈合, 并存在再结晶现象。
\end{abstract}

关键词：铝合金; 直流电脉冲; 损伤; 疲劳; 电阻; 拉伸

作者简介: 乔生儒, 男, 1946 年生, 教授, 博士生导师, 西北工业大学 超高温结构复合材料科技国家重点实验室, 陕西 西安 710072, 电话: 029-88492084, E-mail: blao@nwpu.edu.cn 